\title{
Contrasts in Social and Ecological Assessments of Coral Reef Health in Melanesia
}

\author{
Author(s): Simon Albert, Mark Love, and Tom D. Brewer \\ Source: Pacific Science, 67(3):409-424. 2013. \\ Published By: University of Hawai'i Press \\ DOI: http://dx.doi.org/10.2984/67.3.8 \\ URL: http://www.bioone.org/doi/full/10.2984/67.3.8
}

BioOne (www.bioone.org) is a nonprofit, online aggregation of core research in the biological, ecological, and environmental sciences. BioOne provides a sustainable online platform for over 170 journals and books published by nonprofit societies, associations, museums, institutions, and presses.

Your use of this PDF, the BioOne Web site, and all posted and associated content indicates your acceptance of BioOne's Terms of Use, available at www.bioone.org/page/ terms of use.

Usage of BioOne content is strictly limited to personal, educational, and non-commercial use. Commercial inquiries or rights and permissions requests should be directed to the individual publisher as copyright holder. 


\title{
Contrasts in Social and Ecological Assessments of Coral Reef Health in Melanesia ${ }^{1}$
}

\author{
Simon Albert, ${ }^{2,5}$ Mark Love, ${ }^{3}$ and Tom D. Brewer ${ }^{4}$
}

\begin{abstract}
Numerous studies have explored the "shifting baseline syndrome" (SBS), which suggests that individual perceptions of environmental health are formed by comparing the environment to a "baseline" from the past. Understanding social perceptions of environmental conditions, especially where they differ from ecological assessments, can help guide environmental management efforts. In this study we compared ecological assessments of coral reef health with perceptions of reef health from surveyed residents in five villages in Solomon Islands and Fiji. Comparative analysis suggests that respondents from Solomon Islands perceived their reefs as being degraded, yet based on ecological measurements actually had healthier reefs, while in Fiji fewer people perceived their reefs to be declining in health, yet ecological measurement showed them to be more degraded than Solomon Islands reefs. We found no evidence of baselines "shifting" relative to respondent age in this instance and suggest that these differential baselines and the inverse relationship between local perceptions and ecological measurements may be a result of: (1) differences in the rate of environmental change experienced at local scales; and (2) may also be related to differences in respondent perceptions of "quality of life" at each site. If the success of conservation approaches such as marine protected areas (MPAs) are dependent on local social consensus that natural resources are diminished or degraded, then tracking broader social indicators like "quality of life" and "rates of change" (real and perceived) alongside ecological assessments of environmental health may prove beneficial to conservation practitioners.
\end{abstract}

In 1995 Daniel Pauly (1995) published a short paper that posited that individual perceptions of environmental health are formed

${ }^{1}$ This article is part of a special issue of Pacific Science (vol. 67, no. 3) on the Human Dimensions of Small-Scale and Traditional Fisheries in the Asia-Pacific Region, guest editors John N. (Jack) Kittinger and Edward W. Glazier. Manuscript accepted 26 September 2012.

${ }^{2}$ Centre for Water Futures, School of Civil Engineering, The University of Queensland, St. Lucia 4072, Australia.

${ }^{3}$ School of Social Science, The University of Queensland, St. Lucia, Queensland 4072, Australia.

${ }^{4}$ Australian Research Council Centre for Excellence in Coral Reef Studies, James Cook University, Townsville 4811, Australia.

${ }^{5}$ Corresponding author (e-mail: s.albert@uq.edu.au).

Pacific Science (2013), vol. 67, no. 3:409-424

doi: $10.2984 / 67.3 .8$

(C) 2013 by University of Hawai'i Press

All rights reserved by comparing current environmental conditions to a "baseline" from the past, generally when a person was young. Pauly argued that environmental baselines are subject to "shifts" over generations because each generation calibrates their assessment of environmental health via their first association with the environment, and as ecosystems change so do environmental baselines among society. The "shifting baselines syndrome" (SBS) theory was initially associated with fisheries scientists (Pauly 1995, Sheppard 1995) but has since been applied to other observers of the environment, such as artisanal fishers (SáenzArroyo et al. 2005). The central theme of SBS theory is a temporal mismatch between social perceptions of environmental change and ecological assessments of long-term change, which can reveal historical baselines of pristine or healthy environments. Since Pauly's seminal contribution, numerous scholars have engaged SBS theory but until recently only a 
few empirical studies have documented its existence among other groups (Sáenz-Arroyo et al. 2005, Ainsworth et al. 2008, Bunce et al. 2008, Lozano-Montes et al. 2008, Papworth et al. 2009).

Shifting baselines are important for environmental management because peoples' perceptions of the environment shapes how they interact with it (Ingold 1992, Carrier 2001). Moreover, different modes of socialecological interaction feed back into, and (re)inform, human perceptions of the environment in a mutually constituted manner (Ingold 2000). Thus, how knowledge itself is differently valued, produced, and reproduced has a bearing on interactions such as exploitation and, by consequence, conservation strategies that may be employed. Local ecological knowledge (LEK), for example, can play an important role in informing sustainable fisheries management goals (Hviding and Baines 1994, Berkes and Folke 1998) but may also differ substantially from scientific perceptions of sustainable fisheries management and ecosystem conditions (Hamilton 2003, Foale 2006).

Melanesia is an appropriate context in which to explore the role of social perceptions because inhabitants of local communities are closely associated with the environment, have experienced varying degrees of environmental change within their lifetime, and utilize and manage their nearshore marine resources based on a rich body of LEK (Johannes 1981, Baines 1991, Hviding 1996, Aswani 1997, Adams 1998, Foale 1999, Foale and Macintyre 2000, Hickey 2006). Melanesian societies have a selective understanding of fisheries life cycles (Johannes 1998, Foale 2006), and many people often find it implausible that a species can be harvested to extinction (Foale 2006; Graham Baines, pers. comm., 2007). This, in turn, informs local perceptions of whether or not there is a "crisis" in local fisheries: one of the supposed prerequisites for galvanizing local support behind management prescriptions such as marine protected areas (MPAs) (Locally Managed Marine Area Network 2003).

In Melanesian epistemologies, knowledge is situated and developed in a process and practice-based manner. LEK is thus different from scientific knowledge acquisition in that it is built on active observation and recurrent practical engagement often glossed in the literature as "situated practice" (Hobart 1993, Scott 1998, Ellen et al. 2000, Ingold 2000, Lauer and Aswani 2009, Lauer 2012). This practical and situated modality of LEK production raises a number of issues relating to SBS theory and ecosystem health. First, the experiential dimension of knowledge production bears on the perceived validity of environmental assessments: the fact that just hearing or reading about something (such as marine health) simply does not have the same explanatory "weight" as direct and repeated observation. In short, young people may not accept the oral testimony of their elders regarding past marine health unless this is verified through "situated practice." For example, consider the following refrain from Marovo Lagoon, Solomon Islands: "My father told me about this, but I had to see it for myself before I could really trust it. So I went out to the reefs and found out about it, and now I know" (Baines and Hviding 1992:101). This comment refers to the fact that, in Marovo epistemologies, the acquisition and validation of "knowledge" (inatei) is a matter of transcending through different states of "knowing" (Hviding 1996). From "hearing about something" (avosoa) a state of "knowing" (atei) is attained. Contingent on context and past and subsequent knowledge inputs, atei may transform into "believing" (vatutuana), which, through repeated verification of "seeing for oneself" (omia), is transformed into "trusting" (norua) and can become the state of "being wise" (tetei) (Hviding 1996). Second, in contradiction to western scientific knowledge production, local knowledge is not necessarily open and shared (Hobart 1993), which potentially complicates engaging such information for management or conservation.

The purpose of this study was to compare social perceptions of environmental health with ecological assessments of marine ecosystem health across a range of sites in Melanesia. Here, we describe the Melanesian sites where we conducted our research and the specific methodologies employed in our 
study. Next, we present our results with the view toward identifying and characterizing the factors that influence environmental perceptions of ecosystem health. Finally, we conclude by stressing the need to engage with wider cultural, socioeconomic, and historical contexts when applying the SBS concept outside its original scope (i.e., to fishers or scientists).

\section{MATERIALS AND METHODS}

\section{Case-Study Context}

Melanesia is an area of the western Pacific encompassing Papua New Guinea, Solomon Islands, Vanuatu, New Caledonia, and Fiji. The region is renowned for its rich marine and terrestrial natural resources and its linguistic and cultural diversity. We surveyed three coastal villages in Fiji (Namada, Dravuni, Muaivuso) and two coastal villages in Solomon Islands (Bili, Chea) between 2007 and 2009 (Figure 1). These villages encompass a range of economic and environmental conditions. As in many Pacific island economies, villagers in our case-study areas utilize a diversified or "hybrid" livelihood portfolio, deriving subsistence and income from a dynamic array of sources (Rodman 1987, Ellis 2000).

Namada village lies $90 \mathrm{~km}$ west of Suva on the main island of Viti Levu, Fiji, in a region known as the "coral coast." This area is one of the most popular tourist destinations in Fiji, with a series of large hotels and smaller guesthouses situated along the coast. Nearshore reefs in this region have been degraded by localized sewage inputs and runoff from terrestrial agricultural catchments. Namada village has a population of 178 people, with $10-20$ people employed locally in the tourism industry. In Muaivuso, nearshore reefs are adjacent to a major urban and industrial precinct (rubbish dump, harbor, capital city [Suva]). According to local informants engaged during fieldwork, these reefs have been degraded by land-based pollution and poaching by Suvabased fishermen. Dravuni is a small, isolated island in the Kadavu group $60 \mathrm{~km}$ south of Viti Levu. Dravuni's 150 residents lead a largely subsistence-based existence and rely heavily on large $\left(330 \mathrm{~km}^{2}\right)$ fishing grounds (Jennings and Polunin 1995). Generally, the reefs around Dravuni are characterized by good water quality and high coral cover and fish biomass, which may be due to their remote location.

In contrast to the relatively developed villages of Fiji, Bili and Chea are located in the more remote and less developed Marovo Lagoon in Western Province of Solomon Islands. Marovo Lagoon $\left(700 \mathrm{~km}^{2}\right)$ is considered the longest and best-defined doublebarrier enclosed lagoon in the world (Stoddart 1969). In Solomon Islands, and specifically the Marovo region, the coral reef ecosystems
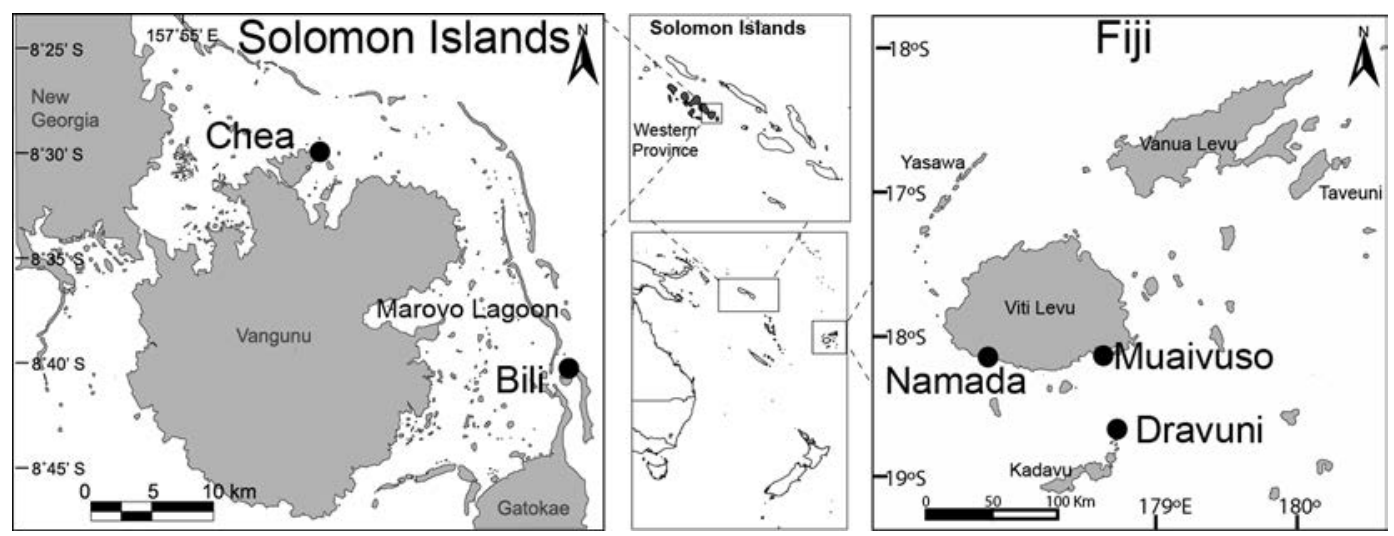

Figure 1. Locations of Solomon Islands and Fiji villages surveyed in this study. 
are among the most biodiverse and intact globally (Green et al. 2006). In Marovo most households derive a major portion of their income from wood carving and handicraft production, followed by marine resource exploitation and the local sale of garden produce. Bili village is located on a passage situated on the southeastern corner of Marovo and has an estimated population of 300 people. Bili has recently been exposed to increasing outside influences from logging companies, tourism, and commercial fishing (namely bait fishing and the live reef fish food trade) (Donnelly 2001, Oliver and Greenpeace Australia-Pacific 2001, Agassi 2005, Kinch et al. 2006). Chea village is located in central Marovo Lagoon, with a population of approximately 350-400 people. Chea is locally recognized as one of the more "traditional" villages in Marovo and is widely considered the basis of Marovo language and custom (Hviding 1996). Chea has a strong resource management ethic based on customary protocols (Forum Economic Ministers Meeting 2006) and has higher levels of community homogeneity compared with Bili (Love 2006).

\section{Social Surveys}

A true/false (agree/disagree) survey instrument was developed to capture individual perceptions of reef degradation and quality of life. Survey questions were developed based on compatibility with ecological assessments of reef health (for reefs adjacent to villages) and to capture personal observations through free-listing exercises and extensive informal discussions (cf. Bernard 2006:354-355). We surveyed individuals from each of the five study villages to elicit assessments of environmental conditions and to pinpoint important local issues relating to quality of life (see Table 1). The survey instrument was pretested before application, and each question was generally included twice with alternate wording and emphasis (i.e., negative or positive). Questions were translated into local vernacular (Marovo for Bili and Chea; Ba Fijian for Dravuni, Namada, and Muaivuso), and the survey was conducted in either written or oral form depending on the literacy level of respondents. Each survey was conducted individually and in private rather than in groups (to avoid the "third-party-present effect") (Bernard 2006:242-243) and generally took 15 minutes to complete. Between 29 and 33 individuals completed the survey from each of the five communities. Respondents were randomly chosen from a list of households provided by a village leader, and a further five households were opportunistically included based on "snowball" sampling to ensure adequate sex and age distribution of the sample. Total coverage: Solomon Islands, $n=59$ (44 males, 15 females); Fiji, $n=96$ (55 males, 41 females). Respondent age was also elicited.

We acknowledge at the outset that this methodological strategy, and our reliance on macro- rather than micro-level socioeconomic indicators, does not capture intracommunity differences between individuals; in other words, by focusing our survey effort at the village level we are presenting a partial assessment of village-level perceptions (see Gupta and Ferguson [1997], Stasch [2010] for a discussion of the limits of such "bounded" analyses). In the case of Fiji, for example, considerable differences between villages themselves can exist (Ward 1965, Waiters 1969). Nevertheless, although there is considerable intercommunity heterogeneity both within and among countries, previous studies in the same villages in Solomon Islands suggest that intracommunity homogeneity, in terms of both economics (Kinch et al. 2006) and sociocultural dimensions (Love 2006), is relatively high, which supports our overall survey approach.

\section{Ecological Surveys}

Coral reef health was measured at each site using four key parameters; live coral cover, macroalgae cover, herbivorous fish biomass, and water quality. Live coral cover and macroalgae cover were classified from digital photos of the substrate taken every $2 \mathrm{~m}$ along six $50 \mathrm{~m}$ transects at each reef (Kohler and Gill 2006, Albert et al. 2008). Herbivorous fish biomass was quantified across eight $50 \mathrm{~m}$ transects at each reef (Albert et al. 2008). 
Water quality (sediments and nutrients) was quantified at each site using standard techniques (Albert et al. 2008). A water quality index was calculated from the sum of the $z$ scores (standard deviations from mean) of dissolved and total nutrients, sediment nutrients, and turbidity for each site (Fabricius et al. 2005). To provide an indication of the relative overall coral reef health at each village, a reef health measure was developed from the sum of the standardized $z$ scores for live coral cover, macroalgae cover, fish biomass, and water quality index at each site (see Table 1).

\section{Data Analysis}

To test for the occurrence of SBS we measured the effect of respondent age on each of the four questions relating to perceived coral reef health using binary logistic regression. We performed this test on the entire population, the Fiji population, the Solomon Islands population, and each village individually to determine whether SBS might occur in some locales and not others. To test whether location was important in explaining perceptions we measured differences in the responses to the four coral reef health questions between nations, between all communities, and between communities within nations, using Fisher's exact test and Pearson's chi-square statistic. Last, we tested for differences between perceived coral reef health and scientifically measured coral reef health for each of the four measures (fish, coral, macroalgae, and water quality) using Kendel's tau correlation.

\section{RESULTS}

\section{Ecological Measurements of Environmental Health}

Reefs adjacent to the Solomon Islands villages (Bili and Chea) had considerably higher live coral cover $(37.8 \%$ and $21.3 \%$, respectively), less macroalgae $(<1 \%)$, higher fish biomass $\left(>10 \mathrm{~g} \mathrm{~m}^{-2}\right)$, and better water quality than the Fijian villages of Namada and Muaivuso (Table 1). Dravuni village in Fiji had high fish biomass (similar to that of the Solomon Is- lands villages), but other indicators suggested substantial degradation (coral, algae, water quality). When standardized into a measured coral reef health index across sites, Bili and Chea were the healthiest reefs, with index values of 94.0 and 85.5, respectively, and Dravuni, Namada, and Muaivuso were more degraded, with index values of 64.1, 27.6, and 10.1, respectively (Table 1 ).

\section{Social Perceptions of Environmental Health}

The majority of Solomon Islands respondents agreed that there are fewer fish today than 10 years ago $(94 \%)$, there is more algae than before $(75 \%)$, water quality is declining (94\%), and the coral reef is dying (100\%) (Table 1). Fijian respondents also had a general perception that the reef was degrading, with $82 \%$ agreeing that there are less fish, there is more algae (72\%), water quality is declining (77\%), and there is more dead coral (89\%). However, responses were generally more positive among Fijian Islanders than among Solomon Islander respondents. Overall, $80 \%$ of Fijians agreed that the reefs were declining, and $91 \%$ of Solomon Islanders agreed that reefs were declining.

Notably, no patterns were evident $(P \geq .05)$ when we tested the effect of age on perceptions within the entire population, the Fiji population, the Solomon Islands population, and each village individually between nations, between villages, or between villages within nations (see Figure 2 for entire population). In addition, there were no significant differences in perceptions between villages within nations (i.e., between Fijian sites or between Solomon Islands sites). There was, however, a significant difference $(P \leq .05)$ between nations in response to some of the questions pertaining to perceived coral reef health, with the Solomon Islands respondents being more negative (Table 2).

\section{Correlations between Ecological Assessments and Local Perceptions of Environmental Health}

Ecological assessments of reef health differed from local perceptions of reef health, with an inverse relationship observed between these 
TABLE 1

Results from Survey Questions, Divided into Categories for Ease of Interpretation and Averages Provided For Appropriate Categories

\begin{tabular}{|c|c|c|c|c|c|c|c|}
\hline \multirow[b]{3}{*}{ Survey Questions } & \multicolumn{7}{|c|}{$\%$ Yes/True } \\
\hline & \multicolumn{2}{|c|}{$\begin{array}{l}\text { Country } \\
\text { Average }\end{array}$} & \multicolumn{2}{|c|}{$\begin{array}{l}\text { Solomon } \\
\text { Islands }\end{array}$} & \multicolumn{3}{|c|}{ Fiji } \\
\hline & $\begin{array}{l}\text { Solomon } \\
\text { Islands }\end{array}$ & Fiji & Bili & Chea & Dravuni & Muaivuso & Namada \\
\hline \multicolumn{8}{|l|}{ Perceived change in coral reef health } \\
\hline $\begin{array}{l}\text { There are not as many fish on the reef now } \\
\text { compared to } 10 \text { yrs ago }\end{array}$ & 94 & 82 & 87 & 100 & 71 & 79 & 92 \\
\hline Dead corals are increasing in numbers & 100 & 89 & 100 & 100 & 96 & 85 & 87 \\
\hline There is more algae than before & 75 & 72 & 72 & 79 & 69 & 79 & 68 \\
\hline The sea is not as clear as it used to be & 94 & 77 & 88 & 100 & 77 & 67 & 87 \\
\hline Average (reef is getting worse) & 91 & 80 & 87 & 95 & 78 & 78 & 84 \\
\hline \multicolumn{8}{|l|}{ Perceived change in quality of life } \\
\hline Life will not be better for us in $10 \mathrm{yrs}^{a}$ & 95 & 43 & 93 & 97 & 69 & 21 & 43 \\
\hline Life is not better now than it was 10 yrs ago $^{a}$ & 94 & 51 & 90 & 97 & 50 & 39 & 62 \\
\hline Life is better in towns than in the village & 1 & 25 & 2 & 0 & 27 & 27 & 22 \\
\hline $\begin{array}{l}\text { The money from fishing/logging is so } \\
\text { important for the country that it is OK if } \\
\text { the reef degrades a little bit }\end{array}$ & 24 & 79 & 47 & 3 & 69 & 67 & 97 \\
\hline \multicolumn{8}{|l|}{ Measured coral reef health } \\
\hline Herbivorous fish biomass $\left(\mathrm{g} \mathrm{m}^{-2}\right)$ & 11.8 & 4.8 & 10.2 & 13.3 & 11.2 & 1.0 & 2.2 \\
\hline Coral (\% cover) & 29.6 & 3.2 & 37.8 & 21.3 & 6.1 & 1.6 & 1.8 \\
\hline Macroalgae (\% cover) & 0.3 & 26.5 & 0.5 & 0.0 & 5.4 & 66.8 & 7.2 \\
\hline Water quality index $(0=$ clean $)$ & 0.1 & 1.0 & 0.0 & 0.2 & 0.5 & 1.0 & 1.4 \\
\hline $\begin{array}{l}\text { Standardized measured reef health } \\
\quad(0=\text { degraded })\end{array}$ & 89.8 & 33.9 & 94.0 & 85.5 & 64.1 & 10.1 & 27.6 \\
\hline
\end{tabular}

a The inverse of the actual survey question for ease of presentation.

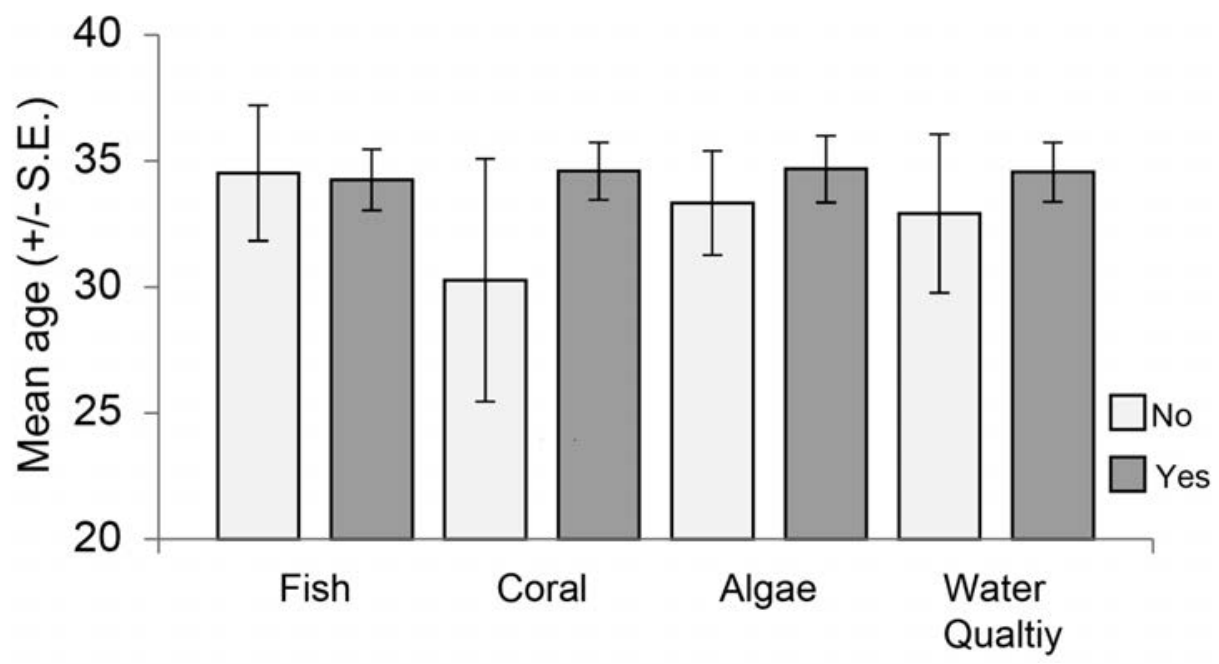

FIGURE 2. Mean respondent age within each response category for each of the four measures of perceived change in reef health. See Table 1 for exact statements used to elicit perceptions. 
TABLE 2

Chi-Square Results of the Relationship between Location and Perceived Change of Environmental Health

\begin{tabular}{lcccc}
\hline \hline Locations & Macroalgae & Coral & Fish & $\begin{array}{c}\text { Water } \\
\text { Quality }\end{array}$ \\
\hline $\begin{array}{c}\text { Between } \\
\text { nations }\end{array}$ & 0.294 & $7.28^{* *}$ & 3.73 & $8.59^{* *}$ \\
$\begin{array}{c}\text { Between } \\
\text { villages }\end{array}$ & 1.89 & $10.48^{b *}$ & $11.11^{b *}$ & $14.75^{b * *}$ \\
$\begin{array}{l}\text { Fiji villages } \\
\text { Solomon } \\
\quad \begin{array}{l}\text { Islands } \\
\text { villages }\end{array}\end{array}$ & 1.21 & $2.08^{b}$ & $4.13^{b}$ & 3.879 \\
& & $d$ & 4.148 & 3.055 \\
\hline
\end{tabular}

\footnotetext{
${ }^{a}$ Fisher's exact test statistic.

${ }^{b}$ Test requirements violated due to inadequate response frequency in contingency table cells.

'Pearson's chi-square statistic.

${ }^{d}$ All responses were positive.

${ }^{*} P \leq .1 ;{ }^{* *} P \leq .05$
}

two measures of coral reef ecosystem health (Table 3, Figure 3). Respondents from Chea were the most pessimistic about reef health despite ecological assessments showing that their reefs were the healthiest of all sites. Conversely, in Muaivuso the respondents had the most positive perceptions of reef health of all sites, despite having among the most degraded reefs according to ecological assessments.

\section{Quality of Life}

As with local perceptions of environmental health, there were also significant differences between countries in respondents' views regarding quality of life. Respondents from Solomon Islands overwhelmingly (95\%) felt that life was worse today than 10 years ago and would continue to get worse in the future. Fijian respondents were far more positive, with only half of respondents agreeing that the quality of life was declining (Table 1). Within countries, Solomon Islanders have similar assessments of quality of life, whereas in Fiji perceptions vary by village. Chea villagers (Solomon Islands) were the most pessimistic about life (97\%) and the reef getting worse/degraded (95\%). The most positive respondents were from Muaivuso in Fiji, with only $30 \%$ believing life was getting worse and $78 \%$ responding that the reef was getting worse (Table 1).

\section{DISCUSSION}

How people perceive and value their environment shapes how they interact with it (Ajzen 1991, Ingold 1992, Carrier 2001). Similarly, normative evaluations of environmental health have an influence on the way people interact with and manage their local environment. The rationale of SBS theory is that individual perception and evaluation of the environment are shaped by comparisons with the health of the environment over "living memory," a process that ultimately alters awareness of longer-term, intergenerational shifts that may have occurred (Pauly 1995). The success of conservation regimes such as MPAs, whether implemented through top-

TABLE 3

Kendel's Tau Correlation Coefficients for the Relationships between Perceived Change of Environmental Health and Ecological Surveys of Environmental Health across Four Parameters

\begin{tabular}{lccccc}
\hline \hline Locations & $n$ & Macroalgae & Coral & Fish & Water Quality \\
\hline Between nations $^{a}$ & 155 & -0.044 & $\mathbf{0 . 2 1 7 * * *}$ & $\mathbf{0 . 1 5 5}^{*}$ & $-0.235^{* *}$ \\
Fiji communities & 96 & 0.085 & 0.125 & -0.035 & 0.111 \\
Solomon Islands communities & 59 & -0.081 & $b$ & $\mathbf{0 . 2 6 5}^{\text {** }}$ & $\mathbf{0 . 2 2 8}^{*}$ \\
\hline
\end{tabular}

Note: Values in boldface show significant correlations that were inverse (i.e., perception of declining health correlated with relatively good health, or perception of improving health correlated with relatively bad health).

${ }^{a}$ Between nations is a test of the national average scientific measurements against perceived change in parameter.

${ }^{b}$ All responses were positive.

${ }^{*} P \leq .1 ;{ }^{* *} P \leq .05 ;{ }^{* * *} P \leq .01$. 


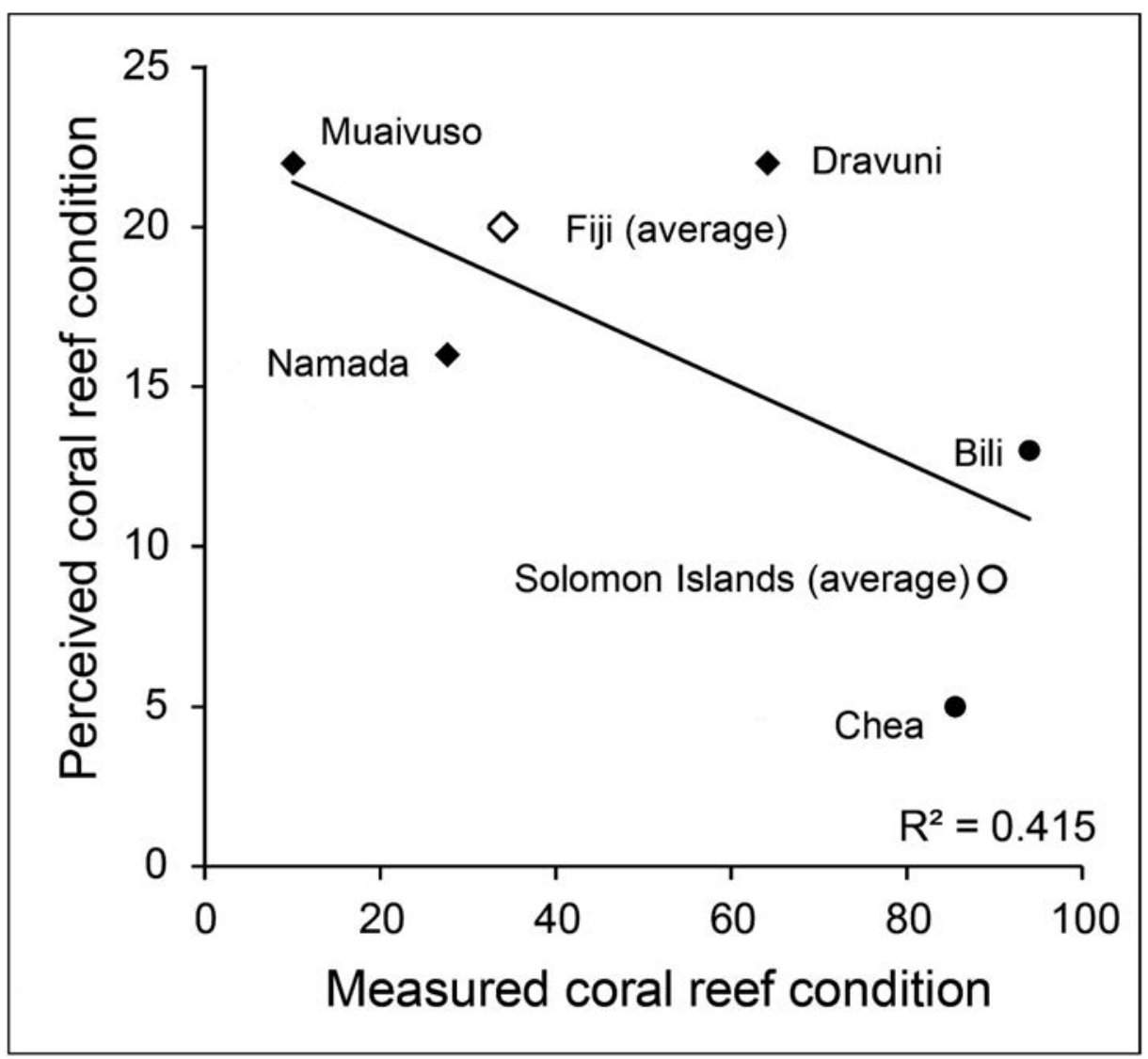

FIGURE 3. Relationship between social perceptions of change in coral reef health (high = good; low = bad) and measured coral reef health (high = good; low $=$ bad) across villages. Social perceptions of coral reef health were quantified, for each village, as the percentage of positive responses to four questions (Table 1) (i.e., if all respondents in a village perceived that all measures of reef health were worse, then the village would score 0 on the $y$-axis, and if they all perceived that all measures of reef health were better, then the village would score 100 on the $y$-axis). Coral reef health was determined via ecological surveys, for each village, as the standardized (equally weighted) values of each of the four measures of reef health (Table 1). The trend line, and associated $r^{2}$ value, which is included for illustrative purposes only, is for the five villages and does not include the national averages.

down government processes or through local, customary management (e.g., tabu areas), may be dependent on social consensus that there is a resource or ecological "crisis" (Locally Managed Marine Area Network 2003). Variability in social perceptions (i.e., lack of a consensus), either within communities or across sites, can limit the effective implementation of management actions at the local or regional level. Indeed, this has been identified as one of the instrumental roles that MPAs can play in conservation: they can help reestablish hu- man expectations about resource and habitat quality by restoring past conditions (Bohnsack 2003).

In Solomon Islands there was clear social consensus among surveyed respondents that the marine environment had degraded in recent times and would continue to do so in the future (Table 1). Respondents agreed that water was getting dirtier, algae were increasing, corals were dying, and fish populations were decreasing. These are typical symptoms of reef degradation as a result of overharvest- 
ing and water quality deterioration (Done 1992, Hughes 1994, Fabricius et al. 2005). In Fiji, on the other hand, there was general perception that reef environments (coral, fish, algae, water) were getting worse, but results showed less consensus across sites (Table 1). Muaivuso villagers (in Fiji) in particular had a more positive outlook on most aspects of reef health, with only $20 \%$ of respondents stating that there would not be enough fish in 10 years, yet based on ecological measurement, they had the most degraded reefs and the lowest fish biomass observed. The comparative data set presented earlier suggests that respondents from Solomon Islands perceived their reefs as degraded yet actually had healthier reefs, and in Fiji fewer people perceived their reefs to be declining in health yet they were more degraded by comparison (Figure 3).

We found no statistically valid evidence for the existence of the "shifting baseline syndrome" relative to age. This may have been limited by the narrow age range of our respondents (15-55) and low mean age of 34 . However we did observe interesting differences between sites, which point to other factors that we believe deserve more attention in the SBS and environmental perceptions literature:

- First, our results demonstrate that the rate at which environmental change has occurred in a given locale may be an important determinant in framing people's perception of the environment. We suggest that different rates of environmental change over longer time scales can result in variable baselines on which respondents frame current perceptions of the environment (Figure 4).

- Second, respondent perceptions of quality of life may also play an important role in shaping local perceptions of environmental health.

\section{Why Place and Rate of Environmental Change Matters}

We observed that the rate of change and the socioeconomic conditions of the place where respondents live have an important bearing on how they viewed the condition of the environment, resulting in differential baselines. We define differential baselines as when normative assessments of ecological health are affected by specific factors associated with: (1) local experience and context ("place"); (2) the rate of change witnessed in an individual's lifetime; and (3) indirectly, due to factors associated with "quality of life" and peoples' "future outlook." In the following paragraphs, we discuss how our interpretation of this data set provides impetus for analysts to move beyond temporal scales alone to more deeply consider the factors that affect normative assessments of ecological health.

In our research, the inverse relationship between local perceptions and ecological assessment of reef health is potentially a consequence of differential baselines for what constitutes a "healthy" reef among respondents. These responses may be driven by different rates of change in environmental health at study sites (Figure 4). For example, although there is a long history of resource extraction in Marovo Lagoon dating back to the 1780s (McKinnon 1975, Bennett 1986, Hviding 1996), these impacts were intermittent and restricted to specific marine resources (e.g., turtle shell, trochus, and bêche-de-mer). These impacts appear to have been of a lesser intensity than current activities such as logging, which results in sedimentation and nutrient additions into the lagoon (see the next section). Thus, reefs in Solomon Islands were previously subjected to less human impacts but have more recently experienced intensive commercial exploitation and land-based sources of pollution, which fall within the living memory of surveyed respondents (Albert 2007). These recent changes in Marovo include a rapid escalation in industrial logging from 1995 to the present, export of fish for the live reef fish food trade from 1996 to 1999, bait fishing for the tuna industry from the 1980 s to the present, and intense local bêche-de-mer harvesting from 1991 to the present (cf. Shearman 1999, Hviding and Bayliss-Smith 2000, Donnelly 2001, Oliver and Greenpeace Australia-Pacific 2001, Hviding 2003; S. Riumana, 2003, report on 


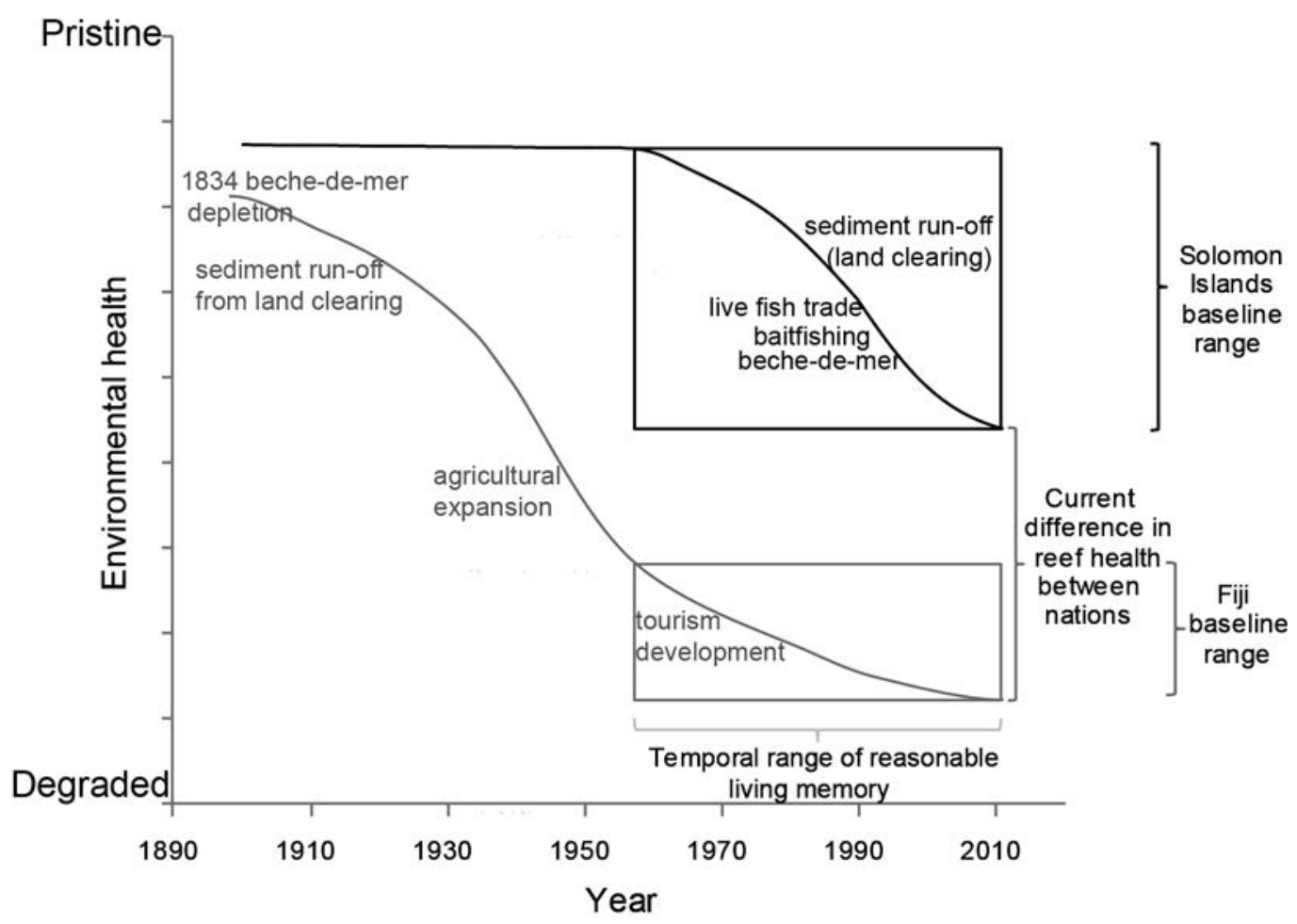

FIgURE 4. Historical reconstruction of coral reef health for the study regions in each of the two nations. Note the difference in potential baseline ranges between the two nations, given the estimated respective coral reef health trajectories and equal temporal range of reasonable living memory. The purpose of this graph is not to provide accurate estimates of environmental condition in each nation but to show the relative rates of degradation in each nation, based upon the historical pressures.

Kumpulam Emas Berhad (KEB), Malaysia, unpubl. data). The people of Marovo, therefore, have observed degradation of reefs within a short time span and can compare current environmental health with a less-degraded level when they were younger.

In Fiji, environmental changes have been occurring over a comparatively longer time span and at greater intensity; in many cases the change had occurred before the birth of the oldest respondents surveyed. Ward (1972), for instance, stated that southeastern Viti Levu was nearly totally depleted of bêche-de-mer by 1834 , with reports suggesting that 35-70 tons of dried Holothuroidea were exported from the area three to four times annually between the years 1830 and
1835. Land-based sources of pollution also may have impacted reefs earlier in Fiji than in Solomon Islands. Stokes (1969), for example, reported that sediment and nutrient runoff from land clearing for cotton, coffee, cattle, and sugarcane began in the late 1800s. In addition, there has been further expansion of agriculture throughout much of Fiji since 1956 (Nunn 1990), land clearing associated with pine plantations since 1960 (Clarke and Thaman 1993), and substantial tourism development throughout much of the country since the 1980s (Mosley and Aalbersberg 2003), all of which are known to result in increased land-based pollution. In 1966 Weber and Woodhead (1970:15) observed reef degradation surrounding Suva (adjacent to 
Muaivuso): "Here, vast areas of fringing reef are now nearly devoid of living coral, yet large, dense stands of Acropora and other corals in their original growth positions, dead but otherwise undamaged, indicate that rich, flourishing coral communities covered these reefs a short time ago." Even the oldest respondents in this survey (aged 55 years) would have grown up with these degraded reefs covered in dead coral and algae. Hence their perceptions of change and future outlook for the reefs reflect the minimal changes they have observed over their lifetime.

Dravuni was an outlier in this inverse relationship between ecological assessments and local perception of reef health, having both relatively healthy reefs and local people displaying a relatively positive outlook in relation to reef health. Dravuni is an offshore reef, and so it has not experienced the degradation of reefs (from land-based runoff) that Namada and Muaivuso have both experienced, which may have affected local perceptions of reef health at that site. Taken together, our results suggest that factors other than age may be important in affecting local perceptions of reef health. In particular, rates of change and the history of place may be integral aspects that affect social perceptions of environmental health and whether such data are congruent with ecological assessments.

The discrepancies between local perceptions of reef health and ecological survey data (Table 1) do not imply that ecological survey data are superior to local knowledge, or vice versa. Instead, differences in such assessments may arise depending on the temporal or spatial scales of inquiry. In Melanesia, where communities have a strong association with a particular area, local perceptions are limited to comparisons with reefs that observers have a long-time association with; hence an individual frame of reference may be driven by temporal baselines rather than spatial comparisons (Figure 4). Conversely, ecological assessments of environmental health often rely on spatial comparisons to "pristine" reference sites; thus they often have a wider frame of reference but may lack the important historical context of place (Berkes et al. 2000).
Quality of Life as a Factor Informing Perceptions of Environmental Health

The World Health Organization defines quality of life as "an individual's perception of their position in life in the context of the culture and value systems in which they live and in relation to their goals, expectations, standards and concerns ..." (World Health Organization 1995). We have conjoined this with "future orientation" based on our question concerning peoples' attitudinal outlook regarding their life in 10 years' time. From these data sets, we derived an overall "quality of life" index that subsumes both quality of life and future outlook indicators. Respondents from Solomon Islands overwhelmingly $(95 \%)$ felt that life was worse now than 10 years ago and that it would continue to be worse in the future. Fijian respondents, by contrast, were far more positive, with only half of the respondents agreeing that life was getting worse. Perceptions of reef health and quality of life were comparable both within Fijian sites and within sites in Solomon Islands. Although this is not evidence of causality, it does suggest that there may be a link between perceptions of quality of life and environmental health.

Perceptions of quality of life may also be associated with rates of environmental change (discussed earlier) and socioeconomic development, which may help explain differences between Solomon Island and Fijian respondents. Intravillage socioeconomic activities and conditions may always be variable (Agrawal and Gibson 1999), but we suggest that these attitudinal differences may be partially associated with place-based variations in people's perceptions of the tradeoff between socioeconomic development and environmental impacts. For example, Fijians were more positive about the present and the future than Solomon Islanders, but they were more than three times as likely to answer affirmatively to the statement that: "The money from commercial fishing/logging is so important for the country that it is OK if the reefs are degraded a little bit" (Fiji, 79\%; Solomon Islands, 24\%). At the country level, 
socioeconomic development may influence local respondents' perceptions of quality of life, which in turn affect attitudinal differences about local environmental conditions. For example, Solomon Islands has relied almost exclusively on resource rents (logging and tuna fishing) as a source of government revenue. Round-log exports, for instance, accounted for between $50 \%$ and $68 \%$ of the country's gross domestic product (GDP) between the years 1990 and 2000 (Central Bank of Solomon Islands 2000, Kabutauka 2000). Yet the country has a poor record of governmental oversight of these activities, and the distribution of monies derived from resource rents is far from optimal (Sheehan 1999, Kabutauka 2000, Solomon Islands Government $2005 a, b)$. Hence respondents are less likely to have benefited directly as a result of logging and fishing, which may have influenced responses about development benefits versus environmental harm. Fiji, by contrast, has relied primarily on tourism, sugar, and, until recently, clothing manufacturing, rather than natural resource rents and has consistently had the highest GDP growth rates in the $\mathrm{Pa}$ cific (Narayan and Prasad 2003). Further, Fiji has constantly had lower birth rates, higher literacy levels, and greater formal employment rates than Solomon Islands (Forum Economic Ministers Meeting 2006). Perhaps of most tangible importance for the local people whom we surveyed, access to basic public health facilities in Marovo is limited due to transportation challenges and limited clinics. These differences in trajectories of socioeconomic development may influence people's attitudinal responses to quality of life indicators and, in turn, their perceptions of local environmental health (Table 1). This may explain why respondents in Fiji report higher quality of life despite the fact that their environment is relatively more degraded. In Solomon Islands, by contrast, respondents report lower quality of life but have less-degraded reef ecosystems. We suggest that these factors are key drivers of peoples' contemporary assessment of quality of life and may explain the incongruity between ecological and social perceptions of coral reef health in our Melanesian sites. A more-focused research effort is required to more fully explore relationships between socioeconomic status and perception of the future and to assess if the links we have observed are indeed causal or simply correlative.

We conclude that incongruity between social perceptions and ecological assessments of reef health are dependent on a wide number of factors beyond simply generational or individual amnesia, as addressed in earlier SBS literature (Papworth et al. 2009). Our research suggests that these factors include the following: (a) the rate of environmental change in a given locale (Bunce et al. 2008); (b) the observers' experience of, and value orientation toward, the environment (Fernbach and Nairn 2007); (c) how knowledge (in this case environmental knowledge) is locally constructed, valued, and transmitted horizontally (among a generation) and vertically (intergenerationally); and (d) individual attitudes associated with "quality of life." It is apparent that strong relationships between the rate of ecological change, perceptions of ecological health, and quality of life may affect social perceptions of ecological conditions in Melanesia. These interactions contribute to a highly complex and dynamic local knowledge system that can inform the baseline of what constitutes a healthy coral reef ecosystem. More studies are needed to better understand the complexity of local knowledge production as it relates to environmental evaluation and change and the multiple forces driving these differential perceptions because they have an important bearing on environmental management in Melanesia.

\section{Literature Cited}

Adams, T. 1998. The interface between traditional and modern methods of fishery management in the Pacific islands. Ocean Coast. Manage. 40:127-142.

Agassi, A. S. 2005. Feast or famine? Fishing for a living in rural Solomon Islands. Pages 107-127 in I. Novaczek, J. Mitchell, and J. Vietayaki, eds. Pacific voices: Equity and sustainability in Pacific island fisheries. Institute of Pacific Studies, University of the South Pacific, Suva, Fiji. 
Agrawal, A., and C. C. Gibson. 1999. Enchantment and disenchantment: The role of community in natural resource management. World Dev. 27:629-649.

Ainsworth, C. H., T. J. Pitcher, and C. Rotinsulu. 2008. Evidence of fishery depletions and shifting cognitive baselines in eastern Indonesia. Biol. Conserv. 141:848-859.

Ajzen, I. 1991. The theory of planned behavior. Organ. Behav. Hum. Decis. Processes 50:179-211.

Albert, S. 2007. Water quality, herbivore and algal interactions on coral reefs in Melanesia: Historic changes, current status and community management. The University of Queensland, Brisbane.

Albert, S., J. Udy, and I. Tibbetts. 2008. Responses of algal communities to gradients in herbivore biomass and water quality in Marovo Lagoon, Solomon Islands. Coral Reefs 27:73-82.

Aswani, S. 1997. Troubled water in southwestern New Georgia, Solomon Islands: Is codification of the commons a viable avenue for resource use regularization. SPC Traditional Marine Resource Management and Knowledge Information Bulletin 18:2-16.

Baines, G. B. K. 1991. Asserting traditional rights: Community conservation in Solomon Islands. Cult Survival Q. 15:49-51.

Baines, G. B. K., and E. Hviding. 1992. Traditional environmental knowledge from the Marovo area of the Solomon Islands. Pages 91-110 in M. Johnson, ed. Lore: Capturing traditional environmental knowledge. International Development Research Centre, Ottawa.

Bennett, J. A. 1986. Wealth of the Solomons: A history of a Pacific archipelago, 18001978. University of Hawai'i Press, Honolulu.

Berkes, F., J. Colding, and C. Folke. 2000. Rediscovery of traditional ecological knowledge as adaptive management. Ecol. Appl. 10:1251-1262.

Berkes, F., and C. Folke. 1998. Introduction: Linking social and ecological systems for resilience and sustainability. Pages 1-26 in F. Berkes and C. Folke, eds. Linking social and ecological systems: Management prac- tices and social mechanisms for building resilience. Cambridge University Press, Cambridge.

Bernard, H. R. 2006. Research methods in anthropology. Sage, London.

Bohnsack, J. A. 2003. Shifting baselines, marine Reserves, and Leopold's biotic ethic. Gulf Caribb. Res. 14:1-7.

Bunce, M., L. D. Rodwell, R. Gibb, and L. Mee. 2008. Shifting baselines in fishers' perceptions of island reef fishery degradation. Ocean Coast. Manage. 51:285-302.

Carrier, J. G. 2001. Limits of environmental understanding: Action and constraint. J. Polit. Ecol. 8:25-43.

Central Bank of Solomon Islands. 2000. Central Bank of Solomon Islands annual report. Honiara, Solomon Islands.

Clarke, W. C., and R. R. Thaman. 1993. Agroforestry in the Pacific islands: Systems for sustainability. United Nations University Press, Tokyo.

Done, T. J. 1992. Phase shifts in coral reef communities and their ecological significance. Hydrobiologia 247:121-132.

Donnelly, R. 2001. Socio-economic environment and the effects of the live reef food fish trade in Marovo Lagoon, Roviana Lagoon, and Ontong Java, Solomon Islands. Australian Centre for International Agricultural Research, Canberra.

Ellen, R., P. Parkes, and A. Bicker. 2000. Indigenous environmental knowledge and its transformations: Critical anthropological perspectives. Harwood Academic Publishers, Amsterdam.

Ellis, F. 2000. Rural livelihoods and diversity in developing countries. University Press, Oxford.

Fabricius, K., G. De'ath, L. McCook, E. Turak, and D. M. Williams. 2005. Changes in algal, coral and fish assemblages along water quality gradients on the inshore Great Barrier Reef. Mar. Pollut. Bull. 51:384-398.

Fernbach, M., and K. Nairn. 2007. Reef recollections: An oral history of the Great Barrier Reef. Great Barrier Reef Marine Park Authority, Townsville, Australia.

Foale, S. J. 1999. Traditional ecological knowledge and biology of the land crab, 
Cardisoma birtipes (Decapoda: Gecarcinidae), at West Nggela, Solomon Islands. Pac. Sci. 53:37-49.

. 2006. The intersection of scientific and indigenous ecological knowledge in coastal Melanesia: Implications for contemporary marine resource management. Int. Soc. Sci. J. 58:129-137.

Foale, S. J., and M. Macintyre. 2000. Dynamic and flexible aspects of property tenure at West Nggela, Solomon Islands: Implications for marine resource management. Oceania 71:30-45.

Forum Economic Ministers Meeting. 2006. Session 1 paper: Economic growth: Lessons learnt from the last ten years, and challenges and opportunities ahead. Pages 35-36. Pacific Islands Forum Secretariat, Honiara. http://www.forumsec.org/ resources/uploads/attachments/

documents/FEMM\%202006\%20

Economic\%20Growth\%20Lessons \%20Learnt.pdf.

Green, A., P. Lokani, W. Atu, P. Ramohia, P. Thomas, and J. Almany. 2006. Solomon Islands marine assessment: Technical report of survey conducted May 13 to June 17, 2004. The Nature Conservancy, Brisbane.

Gupta, A., and J. Ferguson. 1997. Culture, power, place: Explorations in critical anthropology. Duke University Press, Durham, North Carolina.

Hamilton, R. 2003. The role of indigenous knowledge in depleting a limited resource: A case study of the Bumphead Parrotfish (Bolbometopon muricatum) artisanal fishery in Roviana Lagoon, Western Province, Solomon Islands. University of British Columbia, Vancouver.

Hickey, F. R. 2006. Traditional marine resource management in Vanuatu: Acknowledging, supporting and strengthening indigenous management systems. SPC Traditional Marine Resources Management and Knowledge Information Bulletin 20:11-23.

Hobart, M. 1993. An anthropological critique of development: The growth of ignorance. Routledge, London.
Hughes, T. 1994. Catastrophes, phase shifts, and large-scale degradation of a Caribbean coral reef. Science (Washington, D.C.) 265:1547.

Hviding, E. 1996. Guardians of Marovo Lagoon: Practice, place, and politics in maritime Melanesia. University of Hawai' $i$ Press, Honolulu.

- 2003. Contested rainforests, NGOs and projects of desire in Solomon Islands. Int. Soc. Sci. J. 55:539-554.

Hviding, E., and G. B. K. Baines. 1994. Community-based fisheries management, tradition and the challenges of development in Marovo, Solomon Islands. Dev. Change 35:13-39.

Hviding, E., and T. Bayliss-Smith. 2000. Islands of rainforest: Agroforestry, logging and eco-tourism in Solomon Islands. Ashgate Publishing, Aldershot.

Ingold, T. 1992. Culture and the perception of the environment. Pages 39-56 in E. Croll and D. Parkin, eds. Bush base: Forest farm. Routledge, London. 2000. The perception of the environment: Essays on livelihood, dwelling and skill. Routledge, London.

Jennings, S., and N. V. C. Polunin. 1995. Comparative size and composition of yield from six Fijian reef fisheries. J. Fish Biol. 46:28-46.

Johannes, R. E. 1981. Words of the lagoon. University of California Press, Berkeley.

-1998. Government-supported, village-based management of marine resources in Vanuatu. Ocean Coast. Manage. 40:165-186.

Kabutauka, T. T. 2000. Rumble in the jungle: Land, culture and (un)sustainable logging in the Solomon Islands. Page 91 in A. Hooper, ed. Culture and sustainable development in the Pacific. Asia Pacific Press, Canberra.

Kinch, J., P. Mesia, N. Kere, J. Manioli, and K. Bulehite. 2005. Socioeconomic baseline study: Eastern Marovo Lagoon, Solomon Islands. Pages 34-42 in IWP-Pacific Technical Report (International Waters Program). Secretariat of the Pacific Regional Environment Programme, Apia, Samoa. 
http://www.sprep.org/att/publication/ 000536_IWP_PTR35.pdf.

Kohler, K. E., and S. M. Gill. 2006. Coral point count with Excel extensions (CPCe): A visual basic program for the determination of coral and substrate coverage using random point count methodology. Comput. Geosci. 32:1259-1269.

Lauer, M. 2012. Oral traditions or situated practices? Understanding how indigenous communities respond to environmental disasters. Hum. Organ. 71:176-187.

Lauer, M., and S. Aswani. 2009. Indigenous ecological knowledge as situated practices: Understanding fishers' knowledge in the western Solomon Islands. Am. Anthropol. 111:317-329.

Locally Managed Marine Area Network. 2003. Learning framework for the LocallyManaged Marine Area Network. LMMA, Suva.

Love, M. 2006. Projectised epistemologies and unintended consequences: In consideration of environmental change and marine protected areas in Marovo Lagoon, Solomon Islands. Honours thesis, University of Queensland, Brisbane, Australia. http://westernsolomons.uib.no/docs/ Love, \% 20Mark/Love\% 20\% 282006\%29 $\% 20$ Environmental\% 20change\% 20 and $\% 20$ marine $\% 20$ protected $\% 20$ areas $\% 20$ in $\% 20 \mathrm{Marovo} \% 20$ lagoon $\% 20 \% 28 \mathrm{Ma}-$ thesis\%29.pdf.

Lozano-Montes, H. M., T. J. Pitcher, and N. Haggan. 2008. Shifting environmental and cognitive baselines in the upper Gulf of California. Front. Ecol. Environ. 62:7580.

McKinnon, J. 1975. Tomahawks, turtles and traders: A reconstruction in the circular causation of warfare in the New Georgia Group. Oceania 45:290-307.

Mosley, L., and W. Aalbersberg. 2003. Nutrient levels in sea and river water along the 'Coral Coast' of Viti Levu, Fiji, S. Pac. J. Nat. Sci. 21:35-40.

Narayan, P. K., and B. C. Prasad. 2003. Fiji's sugar, tourism and garment industries: A survey of performance, problems and potentials. Fijian Stud. 1:3-27.
Nunn, P. D. 1990. Recent environmental changes on Pacific islands. Geogr. J. 156:125-140.

Oliver, P., and Greenpeace Australia-Pacific, eds. 2001. Caught between two worlds: A social impact study of large and small scale development in Marovo Lagoon, Solomon Islands. Greenpeace Australia-Pacific, Suva.

Papworth, S. K., J. Rist, L. Coad, and E. J. Milner-Gulland. 2009. Evidence for shifting baseline syndrome in conservation. Conserv. Lett. 2:93-100.

Pauly, D. 1995. Anecdotes and the shifting baseline syndrome of fisheries. Trends Ecol. Evol. 10:430.

Rodman, M. 1987. Constraining capitalism? Contradictions of self-reliance in Vanuatu fisheries development. Am. Ethnol. 14:712-726.

Sáenz-Arroyo, A., C. M. Roberts, J. Torre, M. Cariño-Olvera, and R. R. EnríquezAndrade. 2005. Rapidly shifting environmental baselines among fishers of the Gulf of California. Proc. R. Soc. Lond. B Biol. Sci. 272:1957-1962.

Scott, J. C. 1998. Seeing like a state: How certain schemes to improve the human condition have failed. Yale University Press, New Haven, Connecticut.

Shearman, P. 1999. Development options study, Marovo Lagoon, Solomon Islands: Balancing the needs of Marovo and the prosperity of the nation. World Wildlife Fund South Pacific Program, Suva, Fiji.

Sheehan, P. 1999. Solomon Islands forests sector. Pac. Econ. Bull. 15:126-131.

Sheppard, C. 1995. The shifting baseline syndrome. Mar. Pollut. Bull. 30:766-767.

Solomon Islands Government. 2005a. Special audit report into the financial affairs of the Department of Fisheries and Marine Resources. Office of the Auditor-General, Honiara.

- 2005b. Special audit report into the financial affairs of the Department of Forestry, Environment and Conservation. Office of the Auditor-General, Honiara.

Stasch, R. 2010. The category 'village' in Melanesian social worlds: Some theoretical 
and methodological possibilities. Paideuma 56:41-62.

Stoddart, D. R. 1969. Geomorphology of the Marovo elevated barrier reef, New Georgia. Philos. Trans. R. Soc. Lond. B Biol. Sci. 255:383-402.

Stokes, E. 1969. Early plantation experiments in the Fiji Islands. Agric. Hist. 43:379-392.

Waiters, R. F. 1969. Koro: Economic development and social change in Fiji. University Press, Oxford.

Ward, G. R. 1972. The Pacific beche-de-mer trade with special reference to Fiji. Pages 91-123 in G. Ward, ed. Man in the Pacific islands: Essays on geographical change in the Pacific islands. Clarendon Press, Oxford.

Ward, R. G. 1965. Land use and population in Fiji: A geographical study. HMSO, London.

Weber, J. N., and P. M. J. Woodhead. 1970. Ecological studies of the coral predator Acanthaster planci in the South Pacific. Mar. Biol. (Berl.) 6:12-17.

World Health Organization. 1995. The World Health Organization quality of life assessment (WHOQOL): Position paper from the World Health Organization. Soc. Sci. \& Med. 41:1403-1409. 